\title{
ELETROCROMATOGRAFIA CAPILAR: CONTEXTUALIZAÇÃO, ESTADO DA ARTE E PERSPECTIVAS
}

\author{
Milena Pinotti Segato, César Ricardo Silva e Isabel Cristina Sales Fontes Jardim* \\ Instituto de Química, Universidade Estadual de Campinas, CP 6154, 13084-971 Campinas - SP, Brasil
}

Recebido em 25/3/08; aceito em 21/8/08; publiado na web em 26/1/09

\begin{abstract}
CAPILLARY ELECTROCHROMATOGRAPHY: CONTEXTUALIZATION, STATE-OF-THE-ART AND PERSPECTIVES. Capillary electrochromatography (CEC) is a separation technique in which the mobile phase flow is based on the application of a voltage across a packed capillary, which generates an electroosmotic flow that transports the analytes along the capillary toward the detector. As it combines the separation mechanisms of high-performance liquid chromatography (HPLC) and of capillary electrophoresis (CE), CEC can be considered a hybrid of HPLC and CE. This review presents some fundamental aspects of CEC and is focused on the instrumental advances of the technique, such as column technology, operation modes and detection systems, presenting recent papers on these topics and some applications and perspectives about CEC.
\end{abstract}

Keywords: capillary electrochromatography (CEC); capillary separation techniques; pressurized capillary electrochromatography.

\section{INTRODUÇÃo}

Os métodos de separação baseados em técnicas cromatográficas e eletroforéticas têm sido empregados nas diversas áreas da ciência, estando disponíveis em diferentes modos de operação e de arranjos instrumentais. Estes métodos apresentam ampla aplicabilidade por possibilitarem a separação de analitos muito semelhantes em matrizes complexas, como fármacos, alimentos, amostras biológicas e ambientais.

As separações por eletromigração utilizam capilares de diâmetro interno reduzido e a aplicação de campos elétricos elevados que, juntamente com eletrólitos do tampão e grupos iônicos presentes no interior do capilar, promovem a migração dos solutos. Estes são separados de acordo com a velocidade de migração diferencial, que depende da carga e do tamanho do soluto. As separações por eletromigraçao podem ser obtidas utilizando-se as técnicas eletroforéticas, nas quais o mecanismo de separação se baseia exclusivamente na migração diferencial de analitos iônicos ou ionizáveis, como a eletroforese capilar (CE, Capillary Electrophoresis), e por meio de técnicas que envolvem uma combinação dos princípios eletroforético e cromatográfico, denominadas técnicas eletrocromatográficas, ${ }^{1}$ nas quais analitos neutros também podem ser separados. As técnicas eletrocromatográficas podem ser dividas segundo as que empregam fases estacionárias (FE) reais, como a eletrocromatografia capilar (CEC, Capillary Electrochromatography) e a eletrocromatografia planar (PCE, Planar Electrochromatography - sendo esta última realizada em placas como as da cromatografia em camada delgada), e aquelas que utilizam fases pseudo-estacionárias, como a cromatografia eletrocinética micelar (MEKC, Micellar Electrokinetic Chromatography) e a cromatografia eletrocinética em microemulsão (MEEKC, Microemulsion Electrokinetic Chromatography). ${ }^{2}$

No caso da MEKC e MEEKC, as partículas que interagem com os analitos são preparadas adicionando-se substâncias, por exemplo, tensoativos, à solução do eletrólito e estes aditivos podem estar na forma de micelas (determinado arranjo termodinâmico de moléculas de tensoativos, acima da concentração micelar crítica) ou de microemulsão, respectivamente. O material resultante consiste em uma fase dispersa, que está migrando no interior do capilar, por isso a

*e-mail: icsfj@iqm.unicamp.br denominação de fase pseudo-estacionária., ${ }^{2,3}$

$\mathrm{Na} \mathrm{CEC}$, as fases estacionárias utilizadas podem ser as mesmas empregadas em cromatografia líquida de alta eficiência (HPLC, Highperformance Liquid Chromatography), ou com algumas modificações que têm sido o objetivo de vários estudos publicados nos últimos anos. ${ }^{4}$ As fases móveis (FM) utilizadas em CEC consistem de uma mistura de um tampão aquoso com um ou mais solventes orgânicos, como acetonitrila e metanol. ${ }^{5}$ As colunas de CEC são fabricadas a partir de capilares de sílica fundida recorbertos com poliimida. Estes podem ser recheados com partículas de fase estacionária, ${ }^{6}$ capilares abertos, ou seja, um filme de FE recobrindo as paredes internas do capilar $^{7}$ ou capilares preenchidos por um leito contínuo e poroso de FE, denominados colunas monolíticas. ${ }^{8}$ Os capilares empregados em CEC são, geralmente, de 40 a $90 \mathrm{~cm}$ de comprimento e diâmetros internos menores ou iguais a $100 \mu \mathrm{m}$, a fim de minimizar o aquecimento Joule. ${ }^{9}$

Em princípio, a CEC pode ser descrita como uma técnica híbrida da CE e da HPLC, devido à combinação dos mecanismos de separação envolvidos nas duas técnicas. A diferença mais importante entre CEC e HPLC está no fato de que em HPLC, o fluxo da fase móvel é gerado por pressurização, utilizando-se bombas de alta pressão, e em CEC, a fase móvel é forçada a eluir através do capilar por meio da aplicação de um potencial elétrico. Este fenômeno é denominado eletrosmose ou, mais comumente, fluxo eletrosmótico. ${ }^{1,10}$

A Figura 1 mostra uma representação esquemática dos sistemas de HPLC (a), CE (b) e CEC (c).

Para que o fluxo eletrosmótico seja gerado, além do potencial elétrico aplicado, são necessários grupos iônicos no interior do capilar e eletrólitos presentes na FM. ${ }^{1}$ O fluxo eletrosmótico apresenta um perfil de velocidade linear praticamente planar, ou seja, as componentes da velocidade eletrosmótica dos analitos em diferentes regiões do capilar são iguais, enquanto o fluxo pressurizado apresenta um perfil parabólico ou laminar e os analitos no centro do capilar migram mais rapidamente que aqueles próximos à parede do tubo, causando alargamento do pico, diminuindo assim a eficiência da separação. No caso de capilares recheados, a eficiência também é menor quando se utiliza fluxo pressurizado, pois a velocidade será maior nas regiões nas quais há menos partículas de fase estacionária; já o fluxo eletrosmótico mantém os analitos em bandas estreitas, ${ }^{10,11}$ conforme ilustrado na Figura 2. 
a)

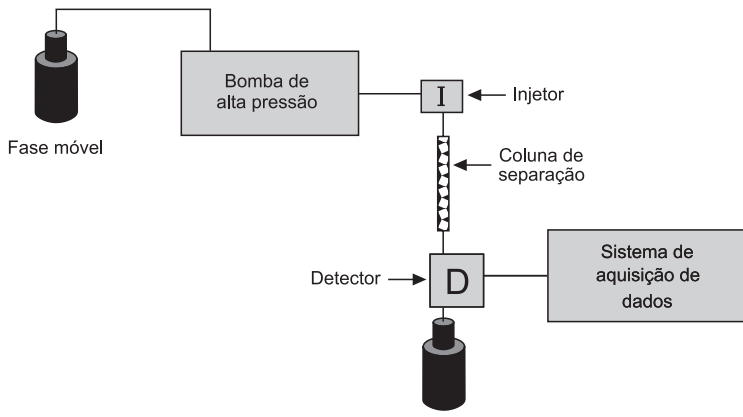

b) Coluna capilar de separação

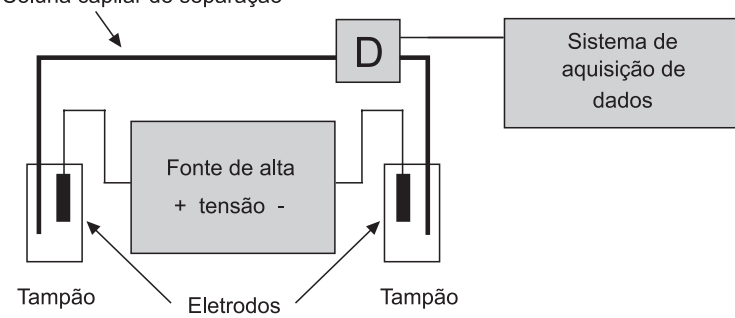

c) Coluna capilar de separação

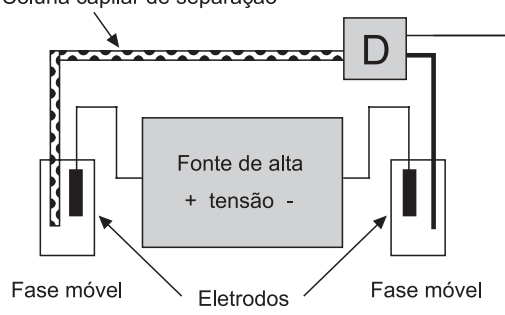

Figura 1. Representação esquemática dos sistemas de a) HPLC, b) CE e c) $C E C$

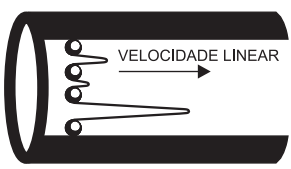

FLUXO PRESSURIZADO

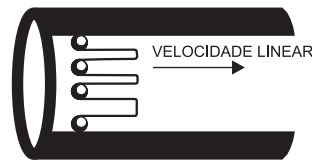

FLUXO ELETROSMÓTICO
Figura 2. Perfil do fluxo pressurizado e do fluxo eletrosmótico no interior de um capilar recheado. Adaptado da ref. 11

Assim como em CE, a CEC permite análises com baixo consumo de solvente e de amostra, e em intervalos de tempo muito curtos, sendo uma técnica com grande potencial de miniaturização. ${ }^{12}$ As análises por CEC podem ser feitas em equipamentos específicos ou em equipamentos de $\mathrm{CE}$, com algumas adaptações, por exemplo, a pressurização nos reservatórios de tampão para evitar bolhas dentro da coluna capilar, ou ainda em sistemas totalmente desenvolvidos em laboratório. ${ }^{13-15}$ Em geral, a CEC apresenta maior seletividade que a $\mathrm{CE}$, devido ao emprego de fases estacionárias no interior do capilar. As eficiências alcançadas em CEC são maiores que em HPLC, podendo chegar a centenas de milhares de pratos por metro, proporcionadas pelo perfil planar do fluxo eletrosmótico. Finalmente, a combinação dos mecanismos eletroforético e cromatográfico permite separar componentes de determinadas amostras que não poderiam ser separados por outras técnicas. ${ }^{8}$

Enquanto a CE e as demais técnicas eletroforéticas são empregadas somente na separação de compostos carregados, as técnicas eletrocromatográficas têm a sua principal aplicação na separação de compostos neutros, já que envolvem interações entre os analitos e as fases estacionárias ou pseudo-estacionárias. No entanto, compostos carregados também podem ser analisados pelas técnicas eletrocromatográficas e algumas aplicações incluem a separação simultânea de compostos neutros, catiônicos e aniônicos por CEC. ${ }^{8,16}$

\section{HISTÓRICO}

Os primeiros experimentos envolvendo a aplicação de potencial elétrico em sistemas cromatográficos foram feitos em 1974, quando Pretorius et al. ${ }^{17}$ mostraram que uma diferença de potencial, ao invés de pressão, poderia ser usada para bombear a fase móvel através de uma coluna recheada com micropartículas de sílica. Entretanto, devido à dissipação deficiente do calor em colunas com diâmetro interno grande, só poderiam ser aplicados campos elétricos fracos, resultando em fluxo eletrosmótico lento e análises demoradas.

No mesmo trabalho, foi introduzido um novo conceito de cromatografia em camada delgada, que hoje é a eletrocromatografia planar, citada anteriormente, em que o solvente é arrastado sobre a placa que contém a fase estacionária por meio de uma diferença de potencial e não apenas por capilaridade, tornando a análise mais rápida. ${ }^{17}$

A primeira separação empregando CEC foi feita por Jorgenson e Lukacs, ${ }^{18}$ em 1981, utilizando eletrodos de grafite e tensão de 30 $\mathrm{kV}$ aplicada a um capilar de $170 \mu \mathrm{m}$ de d.i., recheado com partículas de sílica Partisil-10 ODS-2. Utilizou-se detecção on-column por fluorescência e os analitos separados foram 9-metilantraceno e perileno, com eficiências de 31000 e 23000 pratos $\mathrm{m}^{-1}$, respectivamente. A utilização de capilares possibilitou uma dissipação rápida do calor gerado por aquecimento Joule, permitindo a aplicação de tensões elevadas e a obtenção de separações eficientes e em tempos relativamente curtos.

Posteriormente, Knox e Grant, publicaram dois trabalhos ${ }^{19,20}$ nos quais estudaram alguns aspectos fundamentais da CEC, como o perfil do fluxo eletrosmótico, a sua relação com o diâmetro das partículas da FE e a necessidade de diminuir o diâmetro interno dos capilares para evitar o aquecimento Joule. Os autores mostraram que é possível obter separações mais eficientes, em uma mesma coluna, utilizando fluxos gerados eletricamente ao invés de fluxos pressurizados. A partir destes trabalhos, pôde-se notar um aumento significativo das pesquisas em CEC, como previsto pelos próprios autores. ${ }^{19}$

\section{ESTADO DA ARTE}

Verifica-se a partir de publicações recentes que a CEC ainda está em fase de desenvolvimento. A maioria dos artigos encontrados na literatura descreve os desenvolvimentos da metodologia e da tecnologia, como os diversos tipos de colunas e de fases estacionárias, as adaptações para os modos de operação e o acoplamento com diversos sistemas de detecção. No entanto, são poucos os trabalhos que empregam a técnica simplesmente como uma ferramenta analítica, para a separação de amostras.

\section{Tecnologia de coluna}

A coluna é a parte mais importante do sistema de CEC e o seu desenvolvimento tem sido o foco de várias pesquisas recentes. Alguns artigos descrevem os procedimentos de preparação de novas colunas e outros apenas as melhorias nos processos de confecção das já existentes.

As colunas utilizadas em CEC são classificadas em três tipos: recheadas com partículas de fase estacionária, monolíticas e capilares abertas (open tubular capillary columns). 


\section{Colunas recheadas com partículas de fase estacionária}

As colunas recheadas têm sido as mais empregadas em CEC desde as primeiras aplicações da técnica e consistem de capilares recheados com partículas de sílica com diâmetros de 1,5 a $5 \mu \mathrm{m}$ e quimicamente modificadas. Porém, em CEC as fases estacionárias não são capeadas ou apresentam grupos iônicos, como alquil-sulfonatos, adsorvidos ou ligados à superfície da sílica. ${ }^{16,21}$ Assim como em HPLC, existe disponível comercialmente uma grande variedade de sílicas modificadas que podem ser utilizadas como fases estacionárias em CEC, permitindo diferentes mecanismos de separação, como interação hidrofílica ou hidrofóbica, troca iônica e bioafinidade. ${ }^{4}$ Outra vantagem das colunas recheadas é a elevada capacidade de amostra proporcionada pela grande área superficial do suporte cromatográfico.

Apesar da versatilidade das diferentes fases estacionárias, o bom desempenho e a reprodutibilidade das colunas recheadas dependem do procedimento e da qualidade dos materiais utilizados no seu preparo. ${ }^{9}$ As colunas com recheios deficientes podem apresentar separações com baixa eficiência, pouca resolução e picos assimétricos. ${ }^{9}$ Devido ao processo de enchimento, as colunas capilares recheadas têm custo elevado, são frágeis, a sua vida útil é limitada e, frequentemente, apresentam problemas de reprodutibilidade. ${ }^{9}$

Vários métodos podem ser usados para o enchimento de colunas em CEC. ${ }^{6,9} \mathrm{O}$ mais empregado consiste no enchimento por pressurização de suspensões contendo as partículas de fase estacionária e um solvente adequado, conhecido como enchimento por suspensão a alta pressão. ${ }^{9}$ Alguns métodos utilizam $\mathrm{CO}_{2}$ supercrítico como meio de transporte, outros utilizam enchimento eletrocinético ou por sedimentação (forças gravitacional ou centrípeta). ${ }^{9}$

Maloney e Colón ${ }^{9}$ compararam quatro métodos diferentes de enchimento em CEC, utilizando capilares de $50 \mu \mathrm{m}$ de d.i. e partículas de $3 \mu \mathrm{m}$ Spherisorb C18 e Hypersil CEC C18. Os métodos comparados foram de enchimento por suspensão a alta pressão, com $\mathrm{CO}_{2}$ supercrítico, enchimento eletrocinético e enchimento por força centrípeta. Todos os procedimentos foram feitos pelo mesmo indivíduo para minimizar as fontes de erros. As análises por CEC foram realizadas em um sistema desenvolvido em laboratório, utilizando-se detecção on-column na região do ultravioleta-visível (UV-Vis). As colunas foram avaliadas por meio da separação de uma mistura teste contendo tiouréia, álcool benzílico, tolueno, etilbenzeno, bifenil, dimetilnaftaleno e amilbenzeno. Os autores concluíram que os métodos avaliados foram capazes de produzirem colunas com desempenhos semelhantes e satisfatórios, e que a experiência, adquirida com muita prática e com o tempo, é fator determinante no preparo de colunas eficientes e reprodutíveis. Das técnicas avaliadas, a suspensão a alta pressão é a que está melhor estabelecida, é relativamente fácil de operar e requer poucas exigências, com exceção de solvente adequado para o preparo da suspensão.

Além do processo de enchimento das colunas, é necessário confeccionar os filtros, que são utilizados para manter a fase estacionária no interior do capilar. Infelizmente, a fabricação destes filtros não é reprodutível, provocando variações no desempenho das colunas. ${ }^{22} \mathrm{Um}$ outro problema está relacionado à fragilidade do capilar na posição do filtro, pois para a sua confecção é preciso remover parte da poliimida que recobre o capilar. ${ }^{22}$

O método convencional de fabricação dos filtros envolve a sinterização térmica da sílica ou de uma seção do material de recheio, nas duas extremidades do capilar. ${ }^{22}$ Outros métodos utilizam a polimerização de silicatos ou fotopolimerização na região do ultravioleta (UV) de uma solução contendo monômeros adequados. ${ }^{23}$ Devido às altas temperaturas e à irradiação utilizada nestes métodos, as propriedades da superfície dos filtros e do material de recheio próximo a eles são diferentes das propriedades do material no restante do recheio. Esta diferença gera uma descontinuidade no fluxo eletrosmótico ao longo dos filtros. ${ }^{22}$ Esta variação no fluxo é apontada como uma das principais causas da formação de bolhas em CEC. ${ }^{22}$ As bolhas tornam o fluxo eletrosmótico instável, provocando a quebra da corrente em CEC e, consequentemente, perda da análise. ${ }^{23}$

Buscando minimizar este problema de formação de bolhas, várias alternativas têm sido propostas, entre elas a aplicação de pequena pressão no capilar, a desgaseificação da fase móvel, ${ }^{22}$ o uso de baixas concentrações de tampão ou de baixas temperaturas, ${ }^{22}$ o desenvolvimento de diferentes métodos de fabricação dos filtros ${ }^{23}$ e até a não utilização dos mesmos.22

Oguri et al..$^{23}$ apresentaram, recentemente, um novo método de fabricação de filtros a partir de micropartículas magnéticas (MMP) à base de ferrita. Por meio de testes de estabilidade física e química e de desempenho da coluna, concluíram que as colunas contendo os novos filtros se apresentaram tão estáveis e eficientes quanto as colunas disponíveis comercialmente, que contêm filtros sinterizados. Além disso, os filtros de MMP não promoveram a formação de bolhas e não afetaram o fluxo eletrosmótico. De acordo com os autores, a principal vantagem dos novos filtros é a possibilidade de se utilizar diferentes materiais para rechear colunas, inclusive os mais frágeis, difíceis de serem empregados como recheio, devido aos problemas oriundos dos métodos convencionais de fabricação dos filtros, ${ }^{23}$ como alteração das propriedades dos materiais próximos ao filtro e degradação ocasionada pelas altas temperaturas ou pela radiação UV.

Alguns métodos de confecção de colunas recheadas sem os filtros para CEC vêm sendo desenvolvidos com base na redução do diâmetro do capilar na forma de um afunilamento em apenas uma ou em ambas as extremidades. ${ }^{22}$ No trabalho mais recente sobre estes métodos, Chen et al. ${ }^{22}$ descreveram o preparo de uma coluna recheada com diâmetro reduzido nas duas extremidades do capilar. Os autores avaliaram o desempenho desta coluna na separação de uma mistura de triazinas por CEC acoplada ao espectrômetro de massas (CECMS) com ionização por eletronebulização, e compararam com os resultados obtidos utilizando-se uma coluna com diâmetro reduzido em apenas uma extremidade. Verificaram que o sistema CEC-MS contendo a coluna com diâmetro reduzido nas duas extremidades apresentou uma diminuição no volume morto em relação ao sistema CEC-MS com uma coluna com diâmetro reduzido em apenas uma extremidade. Outra vantagem da redução do diâmetro nas duas extremidades é que, mesmo após várias análises, as partículas permaneceram no interior da coluna, ao contrário do que foi observado para a coluna com diâmetro reduzido em apenas uma extremidade. Nenhuma das colunas apresentou a formação de bolhas durante as análises. Além dessas vantagens, os autores obtiveram alta reprodutibilidade nas análises com a coluna com diâmetro reduzido nas duas extremidades, e apontaram este tipo de coluna como uma alternativa atraente para as aplicações em CEC-MS.22

Além destes novos formatos das colunas capilares que dispensam o uso dos filtros, uma alternativa para CEC é o uso das colunas monolíticas e das capilares abertas.

\section{Colunas monolíticas}

As colunas monolíticas consistem de capilares recheados com um leito contínuo de fase estacionária, altamente poroso e contendo uma rede de canais interconectados, pelos quais passa a fase móvel. Em geral, os monolitos apresentam dois tamanhos de poros, ${ }^{24}$ os macroporos, cujos diâmetros variam entre 2 a $50 \mathrm{~nm}$, e os mesoporos que apresentam diâmetros de até $2 \mathrm{~nm}$. As fases estacionárias monolíticas tiveram a sua primeira aplicação no início da década de 70 , com Ross e Jefferson. ${ }^{25}$ Contudo, os interesses pelos meios contínuos de separação foram despertados somente a partir de 1989, quando Hjertén et al. ${ }^{26}$ empregaram géis de poliacrilamida com baixo 
grau de entrecruzamento como fase estacionária para a separação de proteínas por HPLC.

A aplicação de fases estacionárias monolíticas em CEC surgiu como uma alternativa às colunas recheadas e a sua principal vantagem é que, devido à estrutura contínua dos monolitos e à possibilidade de estarem aderidos à parede do capilar, não existe a necessidade de filtros para manter a fase estacionária no interior da coluna. ${ }^{27}$ Outra vantagem é que as fases monolíticas podem ser preparadas in situ, ou seja, no interior do capilar, sendo este procedimento relativamente mais fácil que os métodos convencionais de enchimento das colunas recheadas. ${ }^{28}$ Além da maior facilidade, o procedimento de obtenção dos monolitos permite a incorporação de diferentes grupos, tornando possível o preparo de fases estacionárias específicas para um determinado tipo de separação e com nível desejado do fluxo eletrosmótico, de acordo com a quantidade de cargas na superfície. ${ }^{28}$ Pode-se ainda otimizar a porosidade e a área superficial das fases monolíticas ajustando-se a concentração dos agentes porogênicos, o que proporciona maior capacidade de amostra. ${ }^{28}$

As fases estacionárias monolíticas podem ser divididas em duas categorias, de acordo com a natureza do material: monolitos de sílica e monolitos à base de polímero orgânico.

Os monolitos de sílica podem ser preparados por três métodos diferentes, incluindo fusão/sinterização das partículas de sílica; entrecruzamento das partículas no interior do capilar por processo sol-gel e, polimerização de um reagente alcoxissilano utilizando o processo sol-gel. ${ }^{29}$ Dentre estes métodos, o último é o mais utilizado. ${ }^{30}$

Uma nova coluna monolítica à base de sílica contendo grupos fenil foi obtida por Yan et al., ${ }^{30}$ empregando co-condensação in situ de tetraetoxissilano (TEOS) com feniltrietoxissilano (PTES) por meio de processo sol-gel envolvendo duas etapas. A coluna contendo os grupos fenil foi testada na separação de compostos neutros e básicos e apresentou altas eficiências e reprodutibilidade, além de um aumento na simetria dos picos dos compostos básicos que, na maioria das fases-reversas, apresentam alargamento, devido à interação com os grupos silanóis residuais.

Recentemente, Zhang et al. ${ }^{31}$ publicaram um trabalho que consistiu no preparo de colunas monolíticas à base de sílica, empregando o processo sol-gel com a polimerização in situ, iniciada por radiação gama que gera radicais a partir do monômero. As colunas preparadas foram avaliadas com sucesso nas separações de compostos neutros por CEC e por micro-HPLC, mostrando que a radiação gama é uma alternativa bastante viável aos tradicionais métodos de polimerização.

Os monolitos à base de polímeros orgânicos são obtidos por reação de polimerização em uma etapa, geralmente iniciada termicamente ou por irradiação na região do UV, a partir de uma solução contendo monômeros funcionais, que determinarão a polaridade resultante do monolito, um agente de entrecruzamento, um iniciador e uma mistura de solventes porogênicos. A formação dos poros durante a polimerização depende da escolha do solvente porogênico, da temperatura e da quantidade do agente de entrecruzamento. ${ }^{32-34}$

As fases monolíticas poliméricas mais empregadas são à base de poliestireno, poliacrilamidas e principalmente de polimetacrilatos que apresentam maior variedade de monômeros funcionais e facilidade de derivatização após a polimerização. ${ }^{24,35}$

Em 2007, Lin et al. ${ }^{36}$ prepararam colunas monolíticas poliméricas porosas de polimetacrilato por polimerização in situ de metacrilato de octadecil (OMA), metacrilato de 3-sulfopropila (SPMA) e dimetacrilato de etileno (EDMA), utilizando a mistura cicloexanol/1,4butadienol como solventes porogênicos. O objetivo foi preparar um monolito com grupos de caráter hidrofóbico, devido ao OMA, e grupos hidrofílicos proporcionados pelo SPMA que também é responsável pela carga necessária para gerar o fluxo eletrosmótico. A vantagem do monolito contendo diferentes grupos funcionais é a maior facilidade de separação de solutos polares e iônicos em relação às fases reversas comuns. Os autores avaliaram o desempenho dos monolitos na separação, por CEC pressurizada, de compostos neutros de diferentes graus de hidrofobicidade e de compostos polares carregados. Eles concluíram que os monolitos contendo ligantes octadecil e grupos sulfonatos apresentam comportamento de retenção típico de fases reversas frente aos compostos apolares e mecanismos de retenção por interação hidrofílica e troca iônica em relação aos analitos polares. A combinação destes mecanismos com a alta velocidade do fluxo eletrosmótico permitiu realizar separações rápidas e com eficiências elevadas. ${ }^{36}$

Os monolitos poliméricos estão sendo mais utilizados em CEC que os monolitos de sílica, devido à maior facilidade e rapidez no preparo e por serem mais estáveis, robustos e apresentarem maior tempo de vida. ${ }^{24}$

\section{Colunas capilares abertas}

As colunas capilares abertas são produzidas a partir do recobrimento das paredes do capilar de sílica com um filme fino de fase estacionária. Este tipo de coluna é mais fácil de se preparar que as colunas recheadas, dispensa o uso dos filtros para manter a fase estacionária no interior do capilar e permite análises mais rápidas, pois há melhor dissipação do calor, quando são aplicadas tensões mais elevadas. Entretanto, estas colunas apresentam menor capacidade de amostra que as colunas recheadas e as monolíticas, devido à menor razão área e volume. ${ }^{37}$

As fases estacionárias empregadas nas colunas capilares abertas são classificadas em quatro tipos: $:^{29}$ quimicamente ligadas, fisicamente ou dinamicamente adsorvidas, à base de polímeros orgânicos e, revestidas por processo sol-gel. As fases quimicamente ligadas envolvem a ligação de grupos orgânicos à superfície da sílica por meio de reações de silanização ou hidrossililação. ${ }^{38}$ As fases estacionárias adsorvidas utilizam interações eletrostáticas entre a superfície da sílica e o ligante (por ex., surfactantes).$^{39}$ Os dois últimos tipos de colunas capilares abertas envolvem processos de polimerização durante o preparo da coluna; nas fases à base de polímeros, utilizam-se monômeros orgânicos ${ }^{40,41}$ e nas fases revestidas por processo sol-gel são empregados os alcóxidos. ${ }^{42,43}$ Ambos os processos utilizam os mesmos métodos de preparo das colunas monolíticas, descritos anteriormente, exceto pelo fato que nos capilares abertos o processo é limitado à cobertura somente da parede do capilar por uma camada fina e porosa do material, ao invés de um meio contínuo que ocupa todo o capilar.

As colunas capilares abertas contendo uma camada porosa de fase estacionária na superfície do capilar são chamadas de colunas capilares abertas de camada porosa (porous layer open tubular) e apresentam maior capacidade de amostra e de retenção que as demais colunas capilares abertas. Contudo, a sua capacidade de amostra ainda é menor que a das colunas recheadas e monolíticas. ${ }^{44}$

Uma coluna aberta de camada porosa com proteína ligada ( $p r o-$ tein-bonded) foi preparada por Huang et al. ${ }^{37}$ utilizando polimerização in situ de metacrilato de 2-hidroxietila e 2-vinil-4,4-dimetilazilactona na presença de 1-decanol como solvente porogênico. Antes da polimerização, foi feita a silanização do capilar de sílica fundida com 3-metacriloxipropiltrimetoxissilano (MAPS). A partir da azilactona presente na camada porosa foi possível fazer a ligação de albumina de soro bovino (BSA) à superfície do polímero. Esta coluna apresentou boa resolução na separação de três aminoácidos por CEC, devido aos sítios de interação fornecidos pelas proteínas ligadas ao polímero. As principais vantagens deste tipo de coluna são a facilidade de preparação e a maior área superficial fornecida pela camada polimérica porosa. As colunas deste tipo podem ser empregadas para investigar a interação entre fármacos e proteínas. ${ }^{37}$ 


\section{Fases estacionárias}

A maioria das fases estacionárias desenvolvidas para CEC baseiase nas fases empregadas em HPLC, principalmente nas do tipo fase reversa e troca iônica. ${ }^{4}$ Entretanto, as fases reversas quando utilizadas em CEC apresentam algumas limitações, sendo a mais importante delas a protonação dos silanóis da sílica em $\mathrm{pH}$ abaixo de 3 , o que provoca uma diminuição do fluxo eletrosmótico, tornando as análises lentas. Outra limitação é que os analitos carregados podem ser fortemente retidos nas fases reversas. Para a análise de moléculas pequenas carregadas, as fases estacionárias do tipo troca iônica são adequadas, no entanto, para a separação de biomoléculas carregadas elas não são muito seletivas, por não apresentarem uma cadeia longa de carbonos para que possa interagir com a cadeia da biomolécula. ${ }^{45}$ Uma alternativa para este tipo de análise são as fases estacionárias de modo misto, que combinam grupos iônicos e cadeias hidrofóbicas no mesmo suporte cromatográfico, e ainda mantêm o fluxo eletrosmótico alto, em uma faixa ampla de $\mathrm{pH}$. Estas fases podem ser obtidas na forma de partículas ou de monolitos. ${ }^{16,46}$ Dois exemplos de colunas monolíticas preparadas com fases de modo misto podem ser encontrados nos trabalhos de Adu et al. ${ }^{16}$ e Lin et al. ${ }^{36}$

Os polímeros de impressão molecular (MIP, moleculary imprinted polymers) também estão sendo bastante empregados em CEC. ${ }^{47,48}$ São preparados por meio da impressão de uma molécula modelo em uma matriz polimérica e apresentam alta seletividade, com sítios de reconhecimento específico, boa estabilidade física e química e fácil preparação. ${ }^{47}$ Zheng et al. ${ }^{47}$ prepararam uma coluna monolítica impressa para CEC utilizando como molécula modelo o tetrapeptídeo YPLG (Tyr-Pro-Ley-Gly), e aplicaram esta coluna no reconhecimento seletivo de oxitocina. A coluna foi testada na análise de uma mistura contendo a oxiticina e outros tipos de proteínas, sendo que o composto de interesse ficou mais retido que as demais biomoléculas, demonstrando o reconhecimento altamente seletivo do monolito impresso para a oxitocina.

A separação de enantiômeros vem sendo bastante explorada em CEC e, neste contexto, diversas pesquisas estão direcionadas para o desenvolvimento de fases estacionárias quirais. Na literatura, encontram-se trabalhos sobre fases estacionárias quirais contidas nos três tipos de colunas empregados em CEC: nas colunas monolíticas, ${ }^{49,50}$ nos capilares recheados com partículas ${ }^{51,52}$ e nas colunas capilares abertas. ${ }^{53-55}$

Em geral, o desenvolvimento de novas fases estacionárias para CEC baseia-se em três princípios, um deles é a capacidade da fase em gerar fluxos eletrosmóticos mais altos e mais estáveis; o segundo é o desempenho da coluna preparada com a nova fase, incluindo a seletividade para diferentes tipos de compostos, a estabilidade e a eficiência; e o terceiro é o preparo da coluna, que deve ser simples, rápido, reprodutível e resultar em colunas de boa qualidade.,45

\section{Modos de operação}

As análises por CEC podem ser feitas utilizando-se diferentes modos de operação, como isocrático, em que a composição da fase móvel é mantida constante durante toda a análise, ou por gradiente, no qual a composição da fase móvel vai sendo alterada ao longo da análise, para que se obtenham melhores resoluções e, na maioria das vezes, análises mais rápidas.

A instrumentação de CEC para eluição em modo isocrático é relativamente simples, podendo-se utilizar os equipamentos de $\mathrm{CE}$ disponíveis. ${ }^{56}$ Os equipamentos disponíveis comercialmente para CEC são os mesmos de CE com modificações que permitem o uso de pressurização nos reservatórios de entrada e saída, apenas para evitar a formação de bolhas e não para impulsionar o solvente.
Em HPLC, o uso de gradiente resolveu os problemas de amostras complexas, contendo analitos com ampla faixa de retenção, cujas análises em modo isocrático eram muito lentas, com baixa resolução para os analitos com retenções próximas e resoluções desnecessárias para os analitos com retenções maiores. Este mesmo princípio foi aplicado em CEC, com sucesso. No entanto, a eluição por gradiente em CEC, ao contrário do modo isocrático, é difícil de ser executada com a instrumentação de CE, sendo necessárias adaptações ou uso de sistemas feitos em laboratório.

O método mais simples de eluição por gradiente em CEC e mais fácil de ser adaptado aos instrumentos comerciais é chamado gradiente-por-etapa (step-gradient), utilizado pela primeira vez por Euerby et $a l .{ }^{57}$ para separar uma mistura teste contendo diuréticos. Neste método, a separação é feita utilizando-se diferentes reservatórios de entrada e saída, contendo a fase móvel em ordem crescente de força cromatográfica e o fluxo do eluente é interrompido a cada troca de fase móvel. ${ }^{57}$ Uma desvantagem deste método é o maior desgaste do capilar, ocasionado pela sua movimentação a cada troca de fase móvel, diminuindo seu tempo de vida.

Apesar deste tipo de gradiente ser útil em algumas aplicações, o uso de gradiente contínuo, além de não causar muito desgaste ao capilar, resulta em separações mais eficientes. O gradiente contínuo em CEC geralmente é obtido por dois métodos. Um deles emprega o sistema de bombas usado em HPLC e o outro utiliza o bombeamento elestrosmótico a partir de dois reservatórios distintos de solvente. ${ }^{10}$ No primeiro método, a separação inicia-se com o eluente de força cromatográfica mais baixa e o solvente de maior força cromatográfica é adicionado continuamente ao reservatório de entrada, por meio de uma bomba de HPLC. . 8,59

Com base neste princípio, Lister et al..$^{60}$ conectaram um sistema de gradiente de micro-HPLC a uma interface de análise por injeção em fluxo (FIA, Flow Injection Analysis) e CEC para separações por gradiente contínuo. Observaram que o fluxo gerado através da coluna de separação era somente de origem eletrosmótica, o que proporcionou separações mais eficientes. Empregando o mesmo sistema, os autores fizeram a separação de uma mistura teste contendo nove compostos, no modo isocrático e por gradiente. A separação no modo isocrático com a melhor resolução ocorreu em $70 \mathrm{~min}$, enquanto a separação por gradiente levou apenas $16 \mathrm{~min}$, com boa resolução para todos os picos e alta reprodutibilidade nos tempos de retenção dos compostos. Além de bons resultados, a interface FIA - CEC aumenta a produtividade dos capilares recheados, pois a injeção e a mudança da composição do solvente são controladas remotamente, diminuindo a manipulação do capilar e prolongando seu tempo de vida. Outra vantagem deste sistema é a facilidade de acoplamento com diferentes sistemas de detecção, como ressonância magnética nuclear $(\mathrm{RMN})^{61}$ e MS, ${ }^{62}$ além da facilidade de automação e possível miniaturização. ${ }^{60}$

O segundo método de gradiente contínuo, que utiliza apenas aplicação de tensão para bombear os solventes, está bem exemplificado pelo sistema desenvolvido por Yan et al., ${ }^{63}$ que consiste de dois reservatórios independentes de solventes, ligados a duas fontes de alta tensão distintas, controladas por um computador. A mistura do gradiente é feita em uma peça na forma de T, que conecta os dois reservatórios de solvente à coluna de separação. São necessários três eletrodos, sendo que dois são colocados nos reservatórios de fase móvel e o outro no reservatório de saída. A injeção da amostra é feita eletrocineticamente, desconectando-se a coluna da peça em $\mathrm{T}$ e colocando-se o terminal de entrada no recipiente de amostra. Uma amostra contendo 16 hidrocarbonetos poliaromáticos foi separada em 90 min por este sistema, com melhor resolução que a apresentada pela separação isocrática. Como o gradiente gerado é puramente eletrosmótico, o sistema parece ideal. Entretanto, o modo como é 
feita a injeção diminui a produtividade do sistema. ${ }^{63}$

Ao contrário dos sistemas com bombas de alta pressão, o sistema eletrosmótico exige uma calibração da composição do eluente em função da tensão, e pequenas mudanças na composição do tampão ( $\mathrm{pH}$, força iônica, viscosidade, constante dielétrica etc.) são suficientes para que seja necessária uma recalibração dos perfis de tensão, consumindo muito tempo entre uma análise e outra. Também se deve levar em consideração que a velocidade da fase móvel não será constante durante a análise, pois o fluxo eletrosmótico também depende da concentração do solvente. ${ }^{63}$

Em CEC é possível aumentar a vazão da fase móvel utilizando-se uma bomba de HPLC, incrementando-se o fluxo eletrosmótico com o uso de pressão. Este modo de operação é denominado eletrocromatografia capilar pressurizada ou pseudo-eletrocromatografia capilar (pCEC) e foi introduzido por Tsuda ${ }^{64} \mathrm{em} \mathrm{1987.} \mathrm{Apesar} \mathrm{deste} \mathrm{modo}$ ser utilizado por diferentes grupos de pesquisa, o arranjo instrumental empregado por cada um é praticamente o mesmo e consiste em um sistema híbrido de micro-HPLC e CE, usando as bombas cromatográficas em um instrumento de $\mathrm{CE}$, com apenas algumas modificações no modo de introdução de amostra, que geralmente é feito utilizando-se os injetores tradicionais de HPLC. O emprego de eluição por gradiente em pCEC é muito fácil, sendo necessária a utilização de programadores de gradiente semelhantes aos empregados em micro-HPLC.

A combinação do uso de pressão e tensão gera um fluxo de fase móvel com perfil intermediário entre o fluxo laminar, resultante da pressão, e o fluxo eletrosmótico linear. Esta combinação se reflete nos valores de eficiência, os quais em pCEC são intermediários entre micro-HPLC e CEC. ${ }^{10}$

Uma das vantagens da pCEC é que o uso de pressão, além de acelerar as análises, diminui a formação de bolhas no capilar, embora isto não seja mais um problema tão frequente em CEC, devido às novas tecnologias de preparo de colunas recheadas. ${ }^{22,23}$ Uma outra vantagem da pCEC é a maior facilidade na introdução de amostra, podendo-se utilizar os injetores de HPLC, o que também elimina os desvios de concentração que ocorrem para analitos carregados quando se utiliza injeção eletrocinética. Apesar destas vantagens, o uso de pressão para impulsionar o fluxo da fase móvel limita às análises em capilares mais curtos e com diâmetros de partículas de fase estacionária maiores que os normalmente usados em CEC. ${ }^{65}$

Sistemas que permitem o uso de diferentes modos de operação, como CEC, pCEC, micro-HPLC e CE, têm sido desenvolvidos em laboratório. ${ }^{65}$ Até o momento, somente duas empresas fabricam equipamentos que permitem empregar estes quatro modos de operação, a Unimicro Technologies, Inc. USA ${ }^{66}$ e a Micro-Tech Scientific, Inc. USA. ${ }^{67}$

\section{Detecção e acoplamento CEC-MS}

Os sistemas de detecção utilizados em CEC podem ser os mesmos disponíveis para CE, sendo os mais empregados em CEC os espectrofotométricos, entre eles os de absorção na região do UV e de fluorescência induzida por laser (LIF, laser induced fluorescence). A CEC também vem sendo acoplada à espectrometria de massas ${ }^{68,69}$ e à ressonância magnética nuclear. ${ }^{61,70}$

A detecção espectrofotométrica é realizada através de uma abertura no capilar, denominada janela de detecção, que é obtida removendo-se a poliimida. Esta janela de detecção pode ser feita em uma região do capilar na qual existe fase estacionária; neste caso, a detecção é denominada in-column, ou em uma região vazia do capilar, cuja detecção é denominada on-column. ${ }^{10}$

Os sistemas de detecção no UV apresentam uma limitação na detectabilidade devido ao pequeno caminho ótico, que é o próprio diâmetro interno do capilar. Uma alternativa para se obter maior detectabilidade é o uso de celas especiais de detecção, como as celas em $\mathrm{Z}$ ou do tipo bolha, que aumentam o caminho ótico, ou ainda podem ser empregados procedimentos on-line de pré-concentração da amostra. ${ }^{71}$

Os detectores baseados em fluorescência induzida por laser apresentam detectabilidade alta, no entanto, na maioria das aplicações são necessárias etapas de derivatização dos analitos para se obterem

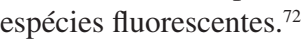

O acoplamento CEC-MS apresenta algumas vantagens frente aos demais sistemas de detecção, entre elas maior seletividade, possibilidade de fornecer informações estruturais e a massa molar dos compostos e a identificação de amostras complexas, mesmo quando há sobreposição de picos.

Diferentes fontes de ionização já foram utilizadas no acoplamento CEC-MS, entre elas a fonte de bombardeio com átomos rápidos (FAB, fast atom bombardment $)^{73,74} \mathrm{e}$ a ionização química à pressão atmosférica (APCI, atmospheric pressure chemical ionization).$^{75}$ Entretanto, a mais utilizada atualmente é a ionização por eletronebulização (ESI, electrospray ionization), que apresenta várias características favoráveis ao acoplamento com CEC, como produção efetiva de íons, robustez, possibilidade de promover o contato elétrico com o sistema de CEC sem interrupção na saída da coluna e compatibilidade com vazões mais baixas, como as utilizadas em CE e CEC. ${ }^{76}$

$\mathrm{O}$ acoplamento entre a fonte de eletronebulização e o sistema de CEC pode ser feito por diferentes interfaces, sendo as mais utilizadas as do tipo fluxo de gás coaxial (sheath-flow), a de junção líquida e a interface sheathless (sem-fluxo). ${ }^{68,76}$

Chen et al. ${ }^{76}$ desenvolveram uma nova interface CEC-ESI do tipo sheathless em que a conexão entre uma coluna capilar aberta e a extremidade do ESI foi feita por meio de um tubo de Nafion, tornando o sistema simples e robusto. Esta nova interface foi aplicada à análise de aminoácidos e peptídeos por CEC-MS, utilizando-se um capilar recoberto com lupamina como fase estacionária, uma polivinilamina linear de alta massa molar. Este polímero foi utilizado para manter um fluxo eletrosmótico adequado e diminuir a adsorção dos analitos na parede do capilar.

Além dos métodos citados, a detecção eletroquímica também pode ser utilizada em CEC. Um exemplo é o método desenvolvido recentemente por Liu et al. ${ }^{77}$ que envolve a determinação de corantes Sudão em tempero culinário, empregando pCEC com detecção amperométrica.

\section{Miniaturização - micro-CEC}

A miniaturização das técnicas de separação é uma das tendências mais relevantes no campo de desenvolvimento de ferramentas analíticas. $^{78,79}$ Os microdispositivos de separação representam uma nova geração de analisadores miniaturizados e oferecem inúmeras vantagens, como portabilidade, pequeno consumo de amostra e solvente, baixo custo, além de análises muito rápidas e capacidade de integração e automação de todos os procedimentos, como limpeza da amostra, pré-concentração, mistura, derivatização, separação e detecção, em um mesmo sistema, que é denominado microssistema de análise total, micro-TAS (micrototal analysis system) ou LOC (lab-on-a-chip). ${ }^{80,81}$

A CEC, por ser uma técnica baseada em migração eletrosmótica, apresenta facilidade para a minituarização. Nesse sentido, sua principal vantagem em relação à micro-HPLC é que não requer um sistema de pressão para gerar o fluxo da fase móvel, sendo necessário apenas o uso de eletrodos e uma fonte de tensão. A CEC foi aplicada pela primeira vez em microdispositivos em 1994, por Jacobson et al.. ${ }^{78}$ Desde então, várias pesquisas têm sido feitas para desenvolvimento e aplicações de micro-CEC,${ }^{79}$ entre elas as que envolvem métodos de introdução de fases estacionárias dentro dos microcanais de um 
dispositivo, ${ }^{12,80}$ assim como métodos que permitem o acoplamento dos microdispositivos de CEC com MS. ${ }^{81,82}$

Recentemente, Faure et al. ${ }^{12}$ apresentaram a preparação in situ de uma fase estacionária monolítica à base de acrilato no interior dos canais de um microdispositivo de PDMS (polidimetilsiloxano) e aplicaram este sistema, com sucesso, na separação de catecolaminas por micro-CEC.

\section{APLICAÇÕES}

Vários artigos foram citados ao longo do texto, sendo que a maioria deles se referia ao desenvolvimento de novas tecnologias, compreendendo colunas, fases estacionárias, sistemas de acoplamento ou detecção, ou aplicações envolvendo separações somente de misturas sintéticas. Os artigos apresentados a seguir envolvem a aplicação da CEC como ferramenta analítica, e em todos eles os métodos de separação foram testados em amostras ou em amostras fortificadas, preparadas a partir da adição de padrões dos analitos à matriz da amostra.

\section{Análise bioquímica}

Guo-Xiang et al. ${ }^{83}$ desenvolveram um método para determinação de metabólitos endógenos presentes na urina de ratos saudáveis e obesos, utilizando pCEC com derivatização em etilcloroformato (ECF), detecção UV e capilares recheados com sílica-C18. Vários métodos têm sido desenvolvidos para a determinação de moléculas endógenas pequenas, entre eles LC-MS, CE-MS, GC-MS e HPLCLIF, ${ }^{83}$ aplicados individualmente ou combinados. Contudo, não existe, até o momento, um único método capaz de analisar a composição completa de metabólitos endógenos devido ao elevado número de moléculas com propriedades químicas bastante distintas. A pCEC foi escolhida para este estudo por ser uma técnica capaz de analisar amostras complexas, apresentando eficiência bastante elevada e com baixo consumo de amostra e de solvente. Os autores empregaram eluição por gradiente, obtendo-se melhor separação dos metabólitos. As amostras de urina foram derivatizadas com etilcloroformato antes das análises por pCEC, pois o uso deste reagente, além de remover as proteínas que podem contaminar o capilar, aumenta a absorção de luz no UV pelos aminoácidos e altera a sua polaridade, permitindo maior detectabilidade e melhor separação. As análises por pCEC foram feitas em um sistema comercial, Trisep ${ }^{\mathrm{TM}}-2100$ (Unimicro Technologies, Inc. USA) que possibilita análises por diferentes técnicas (CEC, pCEC, CE, micro-HPLC). Os autores avaliaram a reprodutibilidade, linearidade e detectabilidade do método, e obtiveram coeficientes de correlação entre 0,9988 e 0,9999 , na faixa de concentração de 1,25 a $500 \mu \mathrm{g} \mathrm{mL} \mathrm{m}^{-1}$ para os padrões de metabólitos. A reprodutibilidade foi investigada utilizando-se uma amostra fortificada e uma amostra de urina de um rato saudável, e as estimativas de desvios padrão relativos (RSD) foram menores que $5 \%(n=6)$. A média das recuperações para todos os compostos ficou entre 95,9 e $103,2 \%$, com RSD menor que $1,0 \%$. Como era esperado, devido à diferença na dieta dos grupos, os eletrocromatogramas das amostras de urina dos ratos obesos apresentaram diminuição nos níveis de três metabólitos, em relação aos resultados das amostras de urina dos ratos saudáveis. Os resultados mostraram que o método desenvolvido é preciso e apresenta boa detectabilidade para determinação de metabólitos endógenos em amostras de urina de ratos.

\section{Alimentos}

Jia et al. ${ }^{84}$ apresentaram um método de determinação de vitaminas hidrossolúveis, empregando pré-concentração on-line e utilizando um sistema de pCEC, com detecção no UV e coluna monolítica de sílica-C18 como capilar de separação. Existem vários métodos que podem ser empregados para a determinação de vitaminas solúveis em água, incluindo HPLC e CE, e a maioria deles é problemática por se tratar de uma separação de amostra complexa. Até então, a aplicação de CEC para a separação de vitaminas hidrossolúveis não havia sido investigada. As análises por pCEC foram feitas em equipamento comercial, Trisep ${ }^{\mathrm{TM}}-2100$. Como os volumes de injeção em CEC são baixos e o caminho ótico para detecção no UV é pequeno, em determinadas aplicações são necessárias técnicas de pré-concentração para aumentar a detectabilidade. Para isto, os autores avaliaram os efeitos de diferentes matrizes de amostra na pré-concentração on-line e concluíram que as melhores condições foram conseguidas com as amostras preparadas em água e utilizando uma combinação de duas técnicas de pré-concentração: estreitamento de zona com gradiente de solvente (solvent gradient zone sharpening effect) e empilhamento da amostra em campo elevado (field-enhanced sample stacking). Os autores avaliaram o método utilizando dois modos de injeção: A) por pressão combinada com injeção eletrocinética e B) por pressão, e concluíram que o modo $\mathrm{A}$ aumentou a concentração das vitaminas positivamente carregadas, decorrente da maior mobilidade eletroforética destas vitaminas em relação às demais (Figura 3), o que causa

A

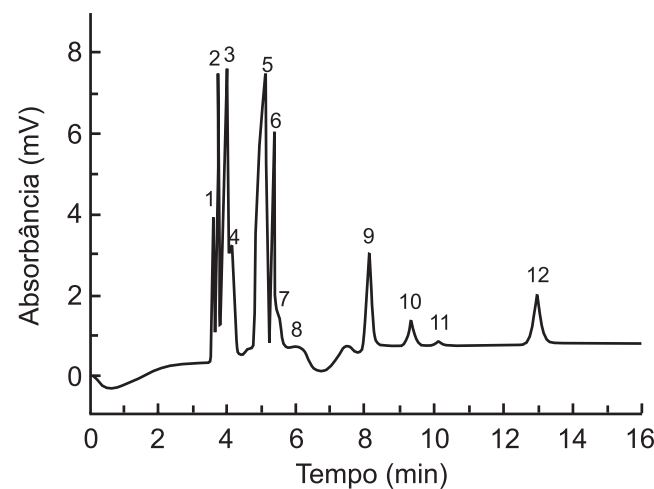

B

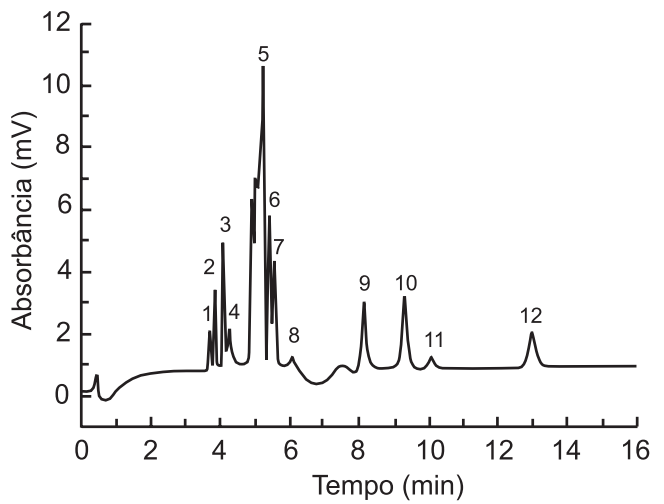

Figura 3. Eletrocromatogramas da mistura de padrões de vitaminas obtidos nos dois modos de injeção: (A) por pressãoleletrocinética e (B) por pressão. Identificação dos analitos: (1) VB1 hidrocloreto de tiamina; (2) VB6-NH2 diidrocloreto de piridoxiamina; (3) VB6-OH hidrocloreto de piridoxina; (4) VB6-H hidrocloreto piridoxal; (5) VC ácido ascórbico; (6) VB3 nicotinamida; (7) NA ácido nicotínico; (8) CP pantotenato de cálcio; (9) VB12 cioanocobalamina; (10) FA ácido fólico; (11) VH D-biotina; (12) VB2 riboflavina. Condições experimentais: concentração das vitaminas $2 \mu \mathrm{g} \mathrm{mL} \mathrm{L}^{-1}$ em água; $V_{i n j}$. $0,413 \mu \mathrm{L}$ (alça de amostragem de $1 \mu \mathrm{L}$ ); eluição isocrática, com fosfato $4 \mathrm{mmol}$ $L^{-1}$ ( $\mathrm{pH} 2$,5) em FM metanol: $\mathrm{H}_{2} \mathrm{O} 26: 74(\mathrm{v} / \mathrm{v})$; vazão ${ }_{F M} 20 \mu \mathrm{L} \mathrm{min}^{-1}$; detecção UV $210 \mathrm{~nm}$. Injeção (A): aplicação de uma tensão negativa (12 kV) na saída da coluna antes da injeção; injeção (B): aplicação de tensão negativa (12 kV) na saída da coluna após a injeção da amostra. Adaptado da ref. 84 
desvios na concentração real da amostra. Os coeficientes de correlação das curvas analíticas (concentração de 1 a $40 \mu \mathrm{g} \mathrm{mL}^{-1}$ ) utilizando o modo de injeção A ficaram entre 0,9928 e 0,9999 , e o modo B ficaram entre 0,9981 e 0,9999 . Uma amostra contendo 12 vitaminas na concentração de $2 \mu \mathrm{g} \mathrm{mL}^{-1}$ foi utilizada para avaliar a reprodutibilidade do método. Os valores de RSD obtidos com o modo de injeção A foram menores que $2,2 \%$ e com o modo B ficaram abaixo de $3,0 \%$ $(n=6)$. Para algumas vitaminas, os limites de detecção $(\mathrm{S} / \mathrm{N}=3)$

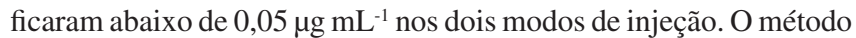
foi aplicado para determinação de vitaminas em amostra de milho, utilizando-se apenas a injeção por pressão. Das 12 vitaminas utilizadas no trabalho, 5 foram identificadas na amostra de milho (Figura 4). A identificação foi feita comparando-se os tempos de retenção dos analitos com os dos padrões e adicionando-se os padrões à amostra de milho. Os experimentos de recuperação foram feitos por fortificação de amostras testemunhas e ficaram acima de 90\% com RSD menor que $2 \%(\mathrm{n}=3)$, mostrando que o método é bastante exato e preciso para a análise destas vitaminas em amostras de milho.

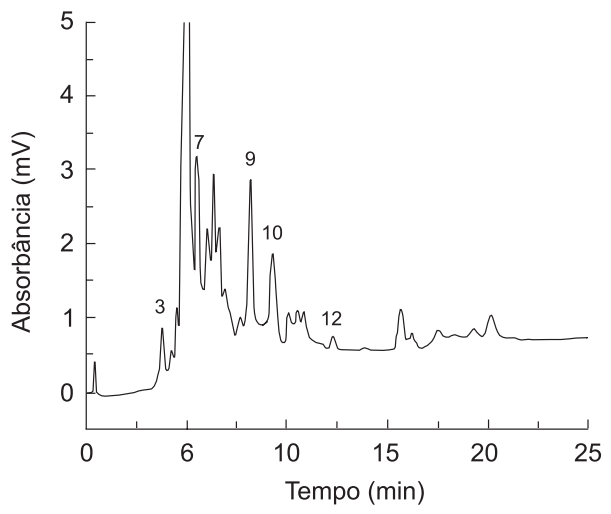

Figura 4. Eletrocromatograma da amostra de milho. A numeração dos picos dos analitos é similar à da Figura 3, e as condições experimentais são as mesmas da Figura 3B. Adaptado da ref. 84.

\section{Aplicação ambiental}

A detecção de minas sub-aquáticas é de importância particular para a Marinha e para providências de remediações ambientais nas regiões costeiras contaminadas por estes dispositivos perigosos. Vários métodos têm sido desenvolvidos para separação e detecção de explosivos nitroaromáticos empregando HPLC, CE e microdispositivos de CE. ${ }^{85}$ O Método 8330 da Agência de Proteção Ambiental NorteAmericana (EPA) ${ }^{86}$ emprega HPLC para a separação de 14 explosivos nitroaromáticos e nitraminas. Apesar de apresentar limites de detecção da ordem de $10 \mu \mathrm{g} \mathrm{L}^{-1}$, este método é demorado e exige grandes quantidades de amostra. Devido a isto, Giordano et al. ${ }^{85}$ desenvolveram dois métodos empregando MEKC e CEC para determinação direta de explosivos nitroaromáticos e nitraminas em amostras de água marinha. As análises foram feitas em um instrumento comercial, Beckman Coulter PACE MDQ CE equipado com detector UV e foram utilizados padrões de 14 explosivos. Os autores verificaram os efeitos da alta concentração salina da água marinha e do tempo de injeção por pressão no desempenho das separações por MEKC, e concluíram que as separações utilizando o tampão borato/colato apresentaram maiores eficiências e melhores resoluções que o tampão borato/SDS (dodecil sulfonato de sódio). Tempos de injeção longos, apesar de aumentarem a detectabilidade, diminuem a resolução para os analitos pouco retidos pela micela. A coluna utilizada para as separações dos explosivos por CEC foi preparada empregando o processo sol-gel e metiltrietoxissilano (MTOS) como monômero, em diferentes concen- trações. Os autores avaliaram as características das fases estacionárias sol-gel preparadas com diferentes concentrações do precursor. As amostras de explosivos foram analisadas por CEC, avaliando-se os efeitos de diferentes tempos de injeção. Em todos os casos, as análises apresentaram menor resolução que em MEKC, com sobreposição de picos em alguns casos. Com o aumento do tempo de injeção, pode-se melhorar a resolução das separações por CEC, mas ainda assim foram menores que MEKC. Apesar da resolução mais baixa, em CEC foram obtidos menores limites de detecção $\left(100 \mu \mathrm{g} \mathrm{L}^{-1}\right)$ que em MEKC $\left(800 \mu \mathrm{g} \mathrm{L}^{-1}\right)$. Os métodos apresentaram resultados complementares em relação à resolução e detectabilidade, no entanto, ambos foram aplicados com sucesso na determinação de explosivos em amostras de água marinha. O método por MEKC é mais adequado para amostras diluídas, enquanto que o método de CEC mostrou bons resultados para amostras sem diluição, ou seja, 100\% de água do mar, submetida somente aos procedimentos de filtração.

\section{PERSPECTIVAS}

Em termos de tecnologia, as principais áreas nas quais se podem esperar os futuros desenvolvimentos da CEC é a de preparo de colunas, incluindo novas fases estacionárias e também a área de microdispositivos.

Na primeira, novos métodos de "manutenção" das partículas de fases estacionárias no interior dos capilares recheados deverão ser desenvolvidos, principalmente aqueles que facilitem o acoplamento com CEC-ESI-MS, como a redução do diâmetro nas extremidades dos capilares. Poderão ser desenvolvidas novas fases estacionárias, mais estáveis, com alta seletividade, elevada capacidade de amostra e maior reprodutibilidade, já que esta é uma desvantagem da CEC em relação à micro-HPLC.

$\mathrm{Na}$ área dos microdispositivos, que é a mais recente em CEC, novos métodos de incorporação de diferentes tipos de fases estacionárias no interior dos micro-canais deverão ser desenvolvidos, assim como interfaces que facilitem o acoplamento com MS.

A CEC tem se mostrado uma técnica adequada para aplicações bioquímicas, como a separação de aminoácidos, de peptídeos e de metabólitos, por realizar separações rápidas e eficientes de compostos neutros e carregados, hidrofílicos e hidrofóbicos. Quando desenvolvida na forma de micro-dispositivos e acoplada às técnicas de detecção como MS, nos chamados micro-TAS, além dos menores consumos de amostra e de solvente, a CEC tem seu desempenho potencializado, representando uma ferramenta analítica poderosa para aplicações em pesquisas na área de genoma e proteoma, que exigem análises rápidas, com altas eficiência, seletividade, detectabilidade e capacidade de processamento. ${ }^{87}$

Com relação às futuras aplicações, a CEC já adquiriu maturidade suficiente em termos de desenvolvimento para que possa ser aplicada em praticamente todos os tipos de análises que atualmente são realizadas por HPLC e CE, estando em desvantagem em algumas delas devido à menor reprodutibilidade e detectabilidade. Apesar disto, novas aplicações ainda são esperadas em CEC, com os mais diversos tipos de amostras.

\section{CONCLUSÃO}

A CEC é uma técnica que, apesar de já ter alcançado vários avanços importantes em termos de instrumentação, ainda está em fase de desenvolvimento e aperfeiçoamento. Ainda são poucos os pesquisadores que optam pela técnica para análise de amostras ambientais, biológicas e de alimentos.

Atualmente, a maioria das análises por CEC é feita em equipamentos de CE, com algumas adaptações, como a aplicação de pressão 
nos reservatórios de tampão para evitar a formação de bolhas dentro da coluna capilar. Alguns grupos de pesquisa utilizam sistemas de CEC totalmente desenvolvidos no laboratório, geralmente empregando bombas de HPLC, que possibilitam o uso de eluição por gradiente. Esta situação é um reflexo da pouca oferta de equipamentos no mercado, que é justificada pelo fato da CEC ser uma técnica recente, que está em nível acadêmico e ainda não se estabeleceu entre as demais técnicas de separação.

Praticamente todas as separações feitas por HPLC e CE podem ser realizadas por $\mathrm{CEC}$ e, assim como $\mathrm{CE}$, permite baixos consumos de solvente e de amostra. Vários sistemas de detecção podem ser utilizados, inclusive o acoplamento com espectrometria de massas e ressonância magnética nuclear.

Até o momento, a CEC tem suas maiores aplicações na área biológica, sendo uma técnica muito atraente para este tipo de pesquisa, graças ao seu potencial de separação de amostras complexas e com alta eficiência, resultante da combinação dos mecanismos eletroforético e cromatográfico.

Apesar de apresentar maior eficiência que a micro-HPLC e maior seletividade que a $\mathrm{CE}$, os resultados obtidos por CEC não são reprodutíveis de análise para análise, principalmente, de coluna para coluna, e os limites de detecção ainda não são tão baixos quantos aos obtidos em HPLC. Além disso, a vida útil dos capilares utilizados em CEC é bastante limitada, ao contrário das colunas de HPLC.

Estas limitações, em conjunto com a falta e disponibilidade de equipamentos avançados no mercado, fazem da CEC uma técnica pouco atraente para aplicação em análises de rotina, como na indústria farmacêutica. Entretanto, o problema da reprodutibilidade pode ser melhorado com novas pesquisas na área de desenvolvimento de tecnologias de colunas mais reprodutíveis e resistentes. Menores limites de detecção podem ser alcançados empregando-se celas de detecção especiais, procedimentos específicos de pré-concentração da amostra, detecção por LIF quando possível, ou por meio do acoplamento CEC-MS. Neste caso, além de maior detectabilidade, a seletividade é extremamente alta, possibilitando identificar os analitos em misturas complexas, mesmo quando há sobreposição de picos.

Esta revisão é uma contribuição importante para os pesquisadores interessados em desenvolver pesquisas empregando CEC, principalmente em nível nacional, uma vez que até o momento se conhecem somente dois artigos científicos de grupos de pesquisa brasileiros ${ }^{88,89}$ Porém, existem várias revisões internacionais sobre fases estacionárias monolíticas aplicadas em CEC,,$^{24,29,34,90-93}$ poucas sobre aplicação ${ }^{94-96}$ e algumas sobre os fundamentos e tecnologia da CEC..$^{11,65,97-102}$ Esta técnica necessita de pesquisas e desenvolvimentos que confirmem a sua aplicabilidade e reprodutibilidade, para que, talvez, se torne competitiva com a HPLC.

\section{AGRADECIMENTOS}

Ao Prof. Dr. C. Pasquini, à Profa. Dra. C. B. G. Bottoli e ao Prof. Dr. I. M. Raimundo Jr. pelas valiosas discussões e sugestões. À FAPESP e ao CNPq pelo suporte financeiro.

\section{REFERÊNCIAS}

1. Fracassi da Silva, J. A.; Coltro, W. K. T.; Carrilho, E.; Tavares, M. F. M.; Quim. Nova 2007, 30, 740.

2. Klampfl, C. W.; Buchberger, W.; Anal. Bioanal. Chem. 2007, 388, 533.

3. Li, S. F. Y.; Capillary Electrophoresis: Principles, Practice and Applications, $1^{\text {st }}$ ed., Journal of Chromatography Library, Elsevier Science B. V.: Amsterdam, 1992, vol. 52

4. Pursch, M.; Sander, L. C.; J. Chromatogr., A 2000, 887, 313.
5. Jiskra, J.; Claessens, H. A.; Cramers, C. A.; J. Sep. Sci. 2003, 26, 1305.

6. Lynen, F.; Buica, A.; de Villiers, A.; Crouch, A.; Sandra, P.; J. Sep. Sci. 2005, 28, 1539 .

7. Yang, Y.; Boysen, R. I.; Matyska, M. T.; Pesek, J. J.; Hearn, M. T. W.; Anal. Chem. 2007, 79, 4942.

8. Kato, M.; Onda, Y.; Sakai-Kato, K.; Toyo'oka, T.; Anal. Bioanal. Chem. 2006, 386, 572.

9. Maloney, T. D.; Colón, L. A.; J. Sep. Sci. 2002, 25, 1215.

10. Krull, I. S.; Stevenson, R. L.; Mistry, K.; Swartz, M. E.; Capillary Electrochromatography and Pressurized Flow Capillary Electrochromatography, $1^{\text {st }}$ ed., HNB Publishing: New York, 2000.

11. Dorsey, J. G.; Microchem. J. 1999, 61, 6.

12. Faure, K.; Blas, M.; Yassine, O.; Delaunay, N.; Crétier, G.; Albert, M.; Rocca, J. L.; Electrophoresis 2007, 28, 1668.

13. Lü, H.; Wu, X.; Xie, Z.; Lin, X.; Guo, L.; Yan, C.; Chen, G.; J. Sep. Sci. 2005, 28, 2210

14. Liu, S.; Xie, Z.; Wu, X.; Lin, X.; Guo, L.; Chen, G.; J. Chromatogr., A 2005, 1092, 258.

15. Zeisbergerová, M.; Kost’ál, V.; Srámková, M.; Babica, P.; Bláha, L.; Glatz, Z.; Kahle, V.; J. Chromatogr., B: Anal. Technol. Biomed. Life Sci. 2006, 841,140

16. Adu, J. K.; Lau, S. S.; Watson, D. G.; Euerby, M. R.; Skellern, G. G.; Tettey, J. N. A.; Electrophoresis 2005, 26, 3445.

17. Pretorius, V.; Hopkins, B. J.; Schieke, J. D.; J. Chromatogr. 1974, 99 , 23.

18. Jorgenson, J. W.; Lukacs, K. D.; J. Chromatogr. 1981, 218, 209.

19. Knox, J. H.; Grant, I. H.; Chromatographia 1987, 24, 135.

20. Knox, J. H.; Grant, I. H.; Chromatographia 1991, 32, 317.

21. Progent, F.; Taverna, M.; Banco, A.; Tchapla, A.; Smadja, C.; J. Chromatogr., A 2006, 1136, 221

22. Chen, C. J.; Chang, C. H.; Her, G. R.; J. Chromatogr, A 2007, 1159, 22.

23. Oguri, S.; Oga, C.; Takeda, H.; J. Chromatogr., A 2007, 1157, 304.

24. Faria, A. M.; Bottoli, C. B. G.; Jardim, I. C. S. F.; Collins, C. H.; Quim. Nova 2006, 29, 300

25. Ross, W. D.; Jefferson, R. T.; J. Chromatogr. Sci. 1970, 8, 386.

26. Hjertén, S.; Liao, J. L.; Zhang, R.; J. Chromatogr. 1989, 473, 273.

27. Messina, A.; Flieger, M.; Bachechi, F.; Sinibaldi, M.; J. Chromatogr., A 2006, 1120,69

28. Augustin, V.; Jardy, A.; Gareil, P.; Hennion, M. C.; J. Chromatogr., A 2006, 1119, 80

29. Allen, D.; El Rassi, Z.; Electrophoresis 2003, 24, 3962.

30. Yan, L.; Zhang, Q.; Zhang, W.; Feng, Y.; Zhang, L.; Li, T.; Zhang, Y.; Electrophoresis 2005, 26, 2935.

31. Zhang, Y. P.; Fan, L. Q.; Lee, K. P.; Zhang, Y. J.; Choi, S. H.; Gong, W. J.; Microchim. Acta 2007, 158, 353.

32. Svec, F.; Peters, E. C.; Sykora, D.; Fréchet, J. M. J.; J. Chromatogr., A 2000, 887,3 .

33. Hilder, E. F.; Svec, F.; Fréchet, J. M. J.; Electrophoresis 2002, 23, 3934.

34. Stulík, K.; Pacáková, V.; Suchánková, J.; Coufal, P.; J. Chromatogr., B: Anal. Technol. Biomed. Life Sci. 2006, 841, 79.

35. Eeltink, S.; Rozing, G. P.; Schoenmakers, P. J.; Kok, W. T.; J. Chromatogr., A 2006, 1109, 74.

36. Lin, J.; Wu, X.; Lin, X.; Xie, Z.; J. Chromatogr., A 2007, 1169, 220.

37. Huang, T.; Mi, J. Q.; Zhang, X. X.; J. Sep. Sci. 2006, 29, 277.

38. Pesek, J. J.; Matyska, M. T.; J. Sep. Sci. 2004, 27, 1285.

39. Liu, Z.; Zou, H.; Ni, J. Y.; Zhang, Y.; Anal. Chim. Acta 1999, 378, 73.

40. Sawada, H.; Jinno, K.; Electrophoresis 1999, 20, 24.

41. Swart, R.; Kraak, J. C.; Poppe, H.; Trends Anal. Chem. 1997, 116, 332.

42. Hayes, J. D.; Malik, A.; Anal. Chem. 2001, 73, 987. 
43. Constantin, S.; Freitag, R.; J. Chromatogr., A 2000, 887, 253.

44. Eeltink, S.; Svec, F.; Fréchet, J. M. J.; Electrophoresis 2006, 27, 4249.

45. Ohyama, K.; Kuroda, N.; J. Liq. Chromatogr. Relat. Technol. 2007, 30, 833.

46. Ohyama, K.; Shirasawa, Y.; Wada, M.; Kishikawa, N.; Ohba, Y.; Nakashima, K.; Kuroda, N.; Electrophoresis 2004, 25, 3224.

47. Zheng, C.; Liu, Z.; Gao, R.; Zhang, L.; Zhang, Y.; Anal. Bioanal. Chem. 2007, 388, 1137.

48. Liu, Z. S.; Xu, Y. L.; Yan, C.; Gao, R. Y.; Anal. Chim. Acta 2004, 523, 243.

49. Chen, Z.; Nishiyama, T.; Uchiyama, K.; Hobo, T.; Anal. Chim. Acta 2004, 501, 17 .

50. Lämmerhofer, M.; Svec, F.; Fréchet, J. M. J.; Lindner, W.; Anal. Chem. 2000, 72, 4623.

51. Kawamura, K.; Otsuka, K.; Terabe, S.; J. Chromatogr., A 2001, 924, 251.

52. Fanali, S.; Catarcini, P.; Presutti, C.; J. Chromatogr., A 2003, 994, 227.

53. Huang, X.; Zhang, J.; Horváth, C.; J. Chromatogr., A 1999, 858, 91.

54. Hofstetter, H.; Hofstetter, O.; Schurig, V.; J. Microcol. Sep. 1998, 10, 287.

55. Millot, M. C.; J. Chromatogr., B: Anal. Technol. Biomed. Life Sci. 2003, 797, 131.

56. Martínez, J. M. H.; Eeltink, S.; Schoenmakers, P. J.; Kok, W. Th.; Ramos, G. R.; J. Sep. Sci. 2006, 29, 660.

57. Euerby, M. R.; Gilligan, D.; Johnson, C. M.; Bartle, K.; Analyst 1997, 122, 1087.

58. Zhang, Y.; Shi, W.; Zhang, L.; Zou, H.; J. Chromatogr., A 1998, 802, 59.

59. Zhang, L.; Zou, H.; Shi, W.; Ni, J.; Zhang, Y.; J. Cap. Electrophoresis 1998, $5,97$.

60. Lister, A. S.; Rimmer, C. A.; Dorsey, V.; J. Chromatogr., A 1998, 828, 105.

61. Gfrörer, P.; Schewitz, J.; Pusecker, K.; Tseng, L. H.; Albert, K.; Bayer, E.; Electrophoresis 1999, 20, 3.

62. Choudhary, G.; Horváth, Cs.; Banks, J. F.; J. Chromatogr., A 1998, 828, 469.

63. Yan, C.; Dadoo, R.; Zare, R. N.; Rakestraw, D. J.; Anex, D. S.; Anal. Chem. 1996, 68, 2726.

64. Tsuda, T.; Anal. Chem. 1987, 59, 521.

65. Rimmer, C. A.; Piraino, S. M.; Dorsey, J. G.; J. Chromatogr., A 2000, $887,115$.

66. http://www.unimicrotech.com/products_CEC_instrument.htm, acessada em Fevereiro 2008

67. http://www.microlc.com, acessada em Fevereiro 2008.

68. Chang, C. H.; Chen, C. J.; Chuang, Y. C.; Her, G. R.; Electrophoresis 2006, 27, 4303

69. Zheng, J.; Shamsi, S. A.; Electrophoresis 2006, 27, 2139.

70. Schewitz, J.; Gfrörer, P.; Pusecker, K.; Tseng, L. H.; Albert, K.; Bayer, E.; Wilson, I. D.; Bailey, N. J.; Scarfe, G. B.; Nicholson, J. K.; Lindon, J. C.; Analyst 1998, 123, 2835.

71. Tegeler, T.; El Rassi, Z.; J. Chromatogr., A 2002, 945, 267.
72. Kato, M.; Jin, H.; Sakai-Kato, K.; Toyo'oka, T.; Dulay, M. T.; Zare, R. N.; J. Chromatogr., A 2003, 1004, 209.

73. Verheij, E. R.; Tjaden, U. R.; Niessen, W. M. A.; van der Greef, J.; J. Chromatogr. 1991, 554, 339.

74. Gordon, D. B.; Lord, G. A.; Jones, D. S.; Rapid Commun. Mass Spectrom. 1994, 8, 544.

75. Tanaka, Y.; Otsuka, K.; Terabe, S.; J. Pharm. Biomed. Anal. 2003, 30, 1889.

76. Chen, Z.; Boggess, B.; Chang, H. C.; J. Mass Spectrom. 2007, 42, 244.

77. Liu, S.; Zhang, X.; Lin, X.; Wu, X.; Fu, F.; Xie, Z.; Electrophoresis 2007, 28, 1696.

78. Jacobson, S. C.; Hergenröder, R.; Koutny, L. B.; Ramsey, J. M.; Anal. Chem. 1994, 66, 2369

79. Auroux, P. A.; Iossifidis, D.; Reyes, D. R.; Manz, A.; Anal. Chem. 2002, 74, 2637.

80. Jindal, R.; Cramer, S. M.; J. Chromatogr., A 2004, 1044, 277.

81. Yang, Y.; Li, V.; Kameoka, J.; Leeb, K. H.; Craighead, H. G.; Lab Chip 2005, 5, 869 .

82. Lazar, I. M.; Li, L.; Yang, Y.; Karger, B. L.; Electrophoresis 2003, 24, 3655 .

83. Guo-Xiang, X.; Ming-Feng, Q.; Ai-Hua, Z.; Peng, L.; Xue, G.; Wei, J.; Chin. J. Anal. Chem. 2007, 35, 1111.

84. Jia, L.; Liu, Y.; Du, Y.; Xing, D.; J. Chromatogr., A 2007, 1154, 416

85. Giordano, B. C.; Copper, C. L.; Collins, G. E.; Electrophoresis 2006, 27,778 .

86. Test Methods for Evaluating Solid Wastes (SW-846), Method 8330: Nitroaromatics and Nitramines by HPLC, US Environmental Protection Agency, Office of Solid Waste and Emergency Response, Washington, DC, 1994.

87. Kasicka, V.; Electrophoresis 2006, 27, 142.

88. Abrantes, S.; Souza, C. M. O. C. C.; Bastos, P. A.; Nery, V. C.; Silva, M. A. M.; Analytica 2006, 24, 60.

89. Fonseca, F. N; Tavares, M. F. M.; Horváth, C.; J. Chromatogr., A 2007, $1154,390$.

90. Svec, F.; J. Sep. Sci. 2005, 28, 729

91. Bedair, M.; El Rassi, Z.; Electrophoresis 2004, 25, 4110.

92. Smith, N. W.; Jiang, Z.; J. Chromatogr., A 2008, 1184, 416.

93. Eeltink, S.; Svec, F.; Electrophoresis 2007, 28, 137.

94. Eeltink, S.; Kok, W. Th.; Electrophoresis 2006, 27, 84

95. Debowski, J. K.; J. Liq. Chromatogr. Relat. Technol. 2002, 25, 1875.

96. Altria, K. D.; Smith, N. W.; Turnbull, C. H.; Chromatographia 1997, 46, 664.

97. Steiner, F.; Scherer, B.; J. Chromatogr., A 2000, 887, 55.

98. Bartle, K. D.; Myers, P.; J. Chromatogr., A 2001, 916, 3.

99. Smith, N. W.; Carter-Finch, A. S.; J. Chromatogr., A 2000, 892, 219.

100. Choudhary, G.; Apffel, A.; Yin, H.; Hancock, W.; J. Chromatogr., A 2000, 887,85 .

101. Klamphl, C. W.; J. Chromatogr., A 2004, 1044, 131

102. Barrachina, E. B.; Moyano, E.; Galceran, M. T.; Electrophoresis 2004, 24, 1927. 